\title{
Sistematização do Fluxo de Atendimento e Acolhimento para a População Idosa em Unidade de Saúde
}

\author{
Bento, Leandra de Fátima; Paiva, Rebeca Fernandes Rocha; Bento, Ligia \\ Francielly; Fontana, Mariane Benicio \\ Pontifícia Universidade Católica do Paraná - leandradefatimabento@hotmail.com
}

Introdução: o envelhecimento populacional, resultado da queda da taxa de fecundidade e do aumento da expectativa de vida, é um fenômeno mundial. Entretanto a velhice ainda não é vivida em sua plenitude por motivos diversos, entre eles as grandes síndromes geriátricas. Essa realidade que se apresenta, exige uma nova maneira de gerir os serviços responsáveis pelo atendimento dessa população, a fim de ajudar pessoas mais velhas a se manterem saudáveis e ativas. Objetivo: Propor uma readequação do fluxo de atendimento e acolhimento do idoso, por meio de capacitação dos profissionais e reorganização este fluxo na Unidade de Saúde. Método: Trata-se de uma pesquisa social com caráter dialético e abordagem qualitativa. Foi idealizado para uma Unidade de Saúde Estratégia em Saúde da Família e sua implantação prevê quatro encontros com os envolvidos. o primeiro para apresentação da proposta, sensibilização e definição dos profissionais que serão a referência do atendimento (médico e enfermeiro). no segundo serão abordados conceitos relacionados ao envelhecimento e discutidas maneiras de aprimorar o acolhimento na Unidade de Saúde, as quais serão aplicadas posteriormente; neste momento o fluxo de atendimento deverá ser definido conforme a realidade local. o terceiro encontro será destinado à capacitação dos profissionais de referência sobre avaliação multifuncional do idoso e às alterações no fluxo estabelecido anteriormente, se necessário. por fim, acontecerá uma capacitação sobre as especificidades do idoso, detecção de problemas e orientações simples e compreensíveis. Os encontros serão agendados com a autoridade sanitária local. Resultados: Melhoria no acolhimento da população idosa que não tem possibilidades de ser inclusa nos programas de saúde existentes, captando-a antes do aparecimento das complicações decorrentes do processo de envelhecimento e promovendo o envelhecimento ativo. Conclusão: a capacitação dos profissionais de saúde, associado a melhoria no acolhimento, permitirão que os idosos tenham mais acesso a informações, orientações e cuidados apropriados que o beneficiarão bem como a sua família e estabelecerão um vínculo com a Unidade de Saúde. Desta maneira a promoção do envelhecimento ativo será uma realidade presente na rotina dos profissionais de saúde que estarão melhor habilitados para detectar os riscos pertinentes ao processo de envelhecer, bem como para envolver a população e instigar-lhes uma mudança de hábitos, possibilitando a postergação do declínio funcional característico deste processo.

Bento, Leandra de Fátima; Paiva, Rebeca Fernandes Rocha; Bento, Ligia Francielly; Fontana, Mariane Benicio. Sistematização do Fluxo de Atendimento e Acolhimento para a População Idosa em Unidade de Saúde. In: Anais do Congresso Internacional de Humanidades \& Humanização em Saúde [= Blucher Medical Proceedings, num.2, vol.1]. São Paulo: Editora Blucher, 2014. ISSN 2357-7282

DOI 10.5151/medpro-cihhs-10333 